\title{
sciforum
}

Conference Proceedings Paper

\section{Multi-Component Solid Forms of Organic Compounds}

\author{
Tom Leyssens \\ Published: date \\ Academic Editor: name \\ Université Catholique De Louvain; tom.leyssens@uclouvain.be
}

\begin{abstract}
Having started my career in pharmaceutical industry, my research focuses on the control and use of solid-state forms of API. The solid state of API has an important impact on properties of solid drug forms such as tablets, influencing hygroscopicity, biodisponibility. My research focuses on engineering the solid-state of API adding multiple components to the same solid phase. We showed how multi-component crystallization (co-crystallization) can be used to control the solidstate properties of drug compounds (hygroscopicity, melting point stabilization, ...) ${ }^{1}$ but can be used as well as to expand the patent life-time of a given drug. ${ }^{2}$ In parallel, we also specialize in developing multi-component crystallization processes, upscaling it to the $\mathrm{kg}$ scale. ${ }^{3}$ Doing so, requires a careful control of underlying thermodynamics and kinetics. In a final part of my research, we go one step further, using the specific properties of multi-component systems to develop novel crystallization-based applications. In particular my group has developed a novel type of resolution based on enantiospecific co-crystallization from solution. ${ }^{4}$ We recently expanded this to resolve mandelic acid using preferential co-crystallization ${ }^{5}$ In our latest ground-breaking work, we used the underlying thermodynamics of these systems, to pull them towards a transformation of the racemate into an enantiopure drug in a so-called deracemization process. ${ }^{6}$
\end{abstract}

Keywords: Co-crystals

\section{References}

1. 'Improving nefiracetam dissolution and solubility behavior using a cocrystallization approach'. X. Buol, K. robeyns, C. Caro Garrido, N. Tumanov, L. collard, J. Wouters, T. Leyssens Pharmaceutics 2020, $12,653$.

2. 'Combining API in a dual-drug ternary cocrystal approach'. L. Song, K. Robeyns, N. Tumanov, J. Wouters, T. Leyssens ChemComm 2020, 56, 13229.

3. 'Solution cocrystallization and its applications'. T. Leyssens and J. ter Horst in 'Multi-component Crystals' 2017, 205-236, W. de Gruyter GmbH.

4. 'Innovative chiral resolution using enantiospecific cocrystallization in solution'. G. Springuel, T. Leyssens Cryst. Growth Des. 2012, 12, 3374.

5. 'Chiral resolution of mandelic acid through preferential cocrystallization with nefiracetam'. X. Buol, C. Caro Garrido, K. Robeyns, N. Tumanov, L. collard, J. Wouters, T. Leyssens Cryst. Growth Des. 2020 (in press). 
The 1st International Electronic Conference on Pharmaceutics, 1 - 15 December 2020

6. 'Cocrystallization-Induced Spontaneous Deracemization : A general thermodynamic approach to deracemization'. M. Guillot, J. de Meester, S. Huynen, L. Collard, K. Robeyns, O. Riant, T. Leyssens Angew. Chem. Int. Ed. 2020, 132, 11399.

(C) 2020 by the authors; licensee MDPI, Basel, Switzerland. This article is an open access article distributed under the terms and conditions of the Creative Commons by Attribution (CC-BY) license (http://creativecommons.org/licenses/by/4.0/). 